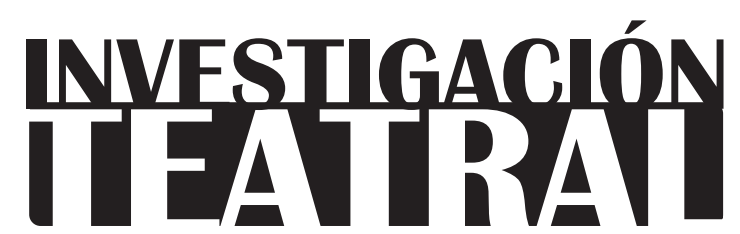

Revista de artes escénicas y performatividad

Vol. 10, Núm. 16

octubre 2019-marzo 2020

Segunda época

ISSN impreso: 1665-8728

ISSN electrónico: 2594-0953

Universidad Veracruzana

\title{
Teatralización popular en el Valle del Mantaro, Perú: negociando la inclusión
}

\author{
Jorge Luis Yangali Vargas*
}

\footnotetext{
* Universidad Nacional del Centro del Perú, Perú. e-mail: jyangali@uncp.edu.pe
}

Recibido: 30 de marzo de 2019

Aceptado: 08 de agosto de 2019

Doi: 10.25009/it.v10i16.2606 


\title{
Teatralización popular en el Valle del Mantaro, Perú: negociando la inclusión
}

\section{Resumen}

Las actuales prácticas culturales, entre ellas las teatrales, se dan en un contexto geopolítico globalizado. En este artículo analizamos algunas prácticas teatrales populares del Perú, en especial del Valle del Mantaro. Se trata de expresiones que, en algunos casos, tienen un lugar de enunciación local y articulan respuestas frente a lógicas coloniales de inclusión sociocultural. En otros, observamos su intención por democratizar el acceso a los bienes culturales, aunque para ello espectacularicen el escenario legitimando las lógicas del mercado neoliberal. La participación en estos espectáculos les permite, a los sujetos comprometidos con la celebración, alcanzar o dar a conocer sus demandas de reconocimiento e inclusión fáctica.

Palabras clave: Desfile alegórico, inclusión social, Camilles, globalización, Perú.

\section{Popular Theatre Expressions in the Mantaro Valley, Peru: Negotiating Inclusion}

\begin{abstract}
Current cultural practices, including theatre, take place in a globalized geopolitical context. This article analyzes some popular theatrical practices in Peru, particularly those of the Valle de Mantaro. In some instances, these locally enunciated expressions articulate responses to the colonial logic of sociocultural inclusion; in others, an intention to democratize the access to cultural assets can be observed, although this usually implies a spectacularization of the stage that legitimizes the neoliberal logic of market. For the individuals involved, participation in these theatrical celebrations represents an opportunity to voice their demands for recognition and factual inclusion.
\end{abstract}

Keywords: allegorical parade, social inclusion, Camilles, globalization, Peru. 


\section{Teatralización popular en el Valle del}

\section{Mantaro, Perú: negociando la inclusión}

\section{Introducción}

E

n el terreno de los estudios sobre las expresiones populares, especialmente aquellos que se ocupan de las danzas del Valle del Mantaro, contamos con los trabajos de Simeón Orellana (Mitos y danzas, "La Tunantada"), José Carlos Vilcapoma ("La maqtada", Waylarsh), Raúl Romero (Identidades múltiples, Debating the Past), Manuel Ráez (Imaginario global), entre otros. Todos ellos han ahondado en la comprensión histórica y antropológica de las danzas que se consideran hegemónicas por su importancia local en dicho contexto, enfocando la correlación entre éstas y su proceso de patrimonialización. Se privilegian danzas como el Waylarsh, la Tunantada, la Huaconada y la Pachahuara. En nuestro caso, abordamos más bien una expresión marginal con pocas posibilidades de ser patrimonializada: los Camilles, que fue creada en la década de los años 70 del siglo xx y tiene la particularidad de incluir, entre sus personajes, a la más variopinta y caótica fauna humana que la fantasía pueda imaginar. Nuestro estudio sigue la línea sugerida por Raúl Romero y, en especial por Manuel Ráez, quienes consideran, en sus análisis, la variable de la globalización.

Para caracterizar el sentido e importancia del surgimiento de una danza como la de los Camilles, procuremos comprender el periodo en el que ésta emerge y al que comúnmente se le denomina globalización. Hablar sobre este fenómeno, en especial de sus efectos sobre la vida en general y sobre la producción cultural en particular, nos lleva a dar cuenta de cuando menos tres modos en los que ha sido entendido.

Por un lado, se tiene la perspectiva triunfalista de los defensores del libre mercado y la postindustria, quienes, ante la debacle tanto del bloque socialista totalitario como de las 
narrativas universalizantes, se advierten como una generación situada en un periodo de crisis, en el tránsito que va de un sistema de producción industrial masificante -con un restringido número de modelos- hacia una ilimitada y "deslumbrante diversidad" (Toffler 248), la cual sería ofertada al habitante de la aldea global (McLuhan, La aldea global). Este habitante tendría la capacidad económica, tecnológica y temporal de consumir y apropiarse de la vasta cultura global. En este enfoque, resulta clave el uso masivo e interactivo de la tecnología, el cual pondría al alcance del consumo de los ciudadanos globales ciertos modelos estéticos que las expresiones artísticas populares habrían asimilado progresiva y vertiginosamente (asimilación que, en principio, genera una dependencia no sólo económica, sino también cultural). Este enfoque resulta positivo, por ende, para quien logre transnacionalizar su condición cultural y humana.

Confrontando tal perspectiva, emerge una mirada crítica y desencantada de la globalización que la concibe como homogeneizadora a escala global (Fredric Jameson citado en Moxey, "Estética de la cultura"). Este otro punto de vista concibe el quehacer artístico y cultural como una forma de resistencia frente al mercantilismo y, por ende, al sistema capitalista. En este entendimiento, muchas de las actuales expresiones artísticas populares serían el reflejo de la avasallante transmundialización cultural, constituyendo, por tanto, el nuevo opio apaciguador frente a las reales condiciones de vida de las mayorías. La globalización implicaría el influjo de las transnacionales, que comprimen el espacio y el tiempo para desterritorializar sus capitales tanto financieros como culturales y simbólicos. Al hacerlo, el consumo es descontrolado y la necesidad de goce no tiene límites.

Una tercera aproximación, igualmente crítica del fenómeno, sería la perspectiva de los estudios provenientes del "sur" (parafraseando a De Sousa Santos, Una epistemología del sur), que entiende a los efectos del capitalismo tardío y la mundialización no en la idea de un tiempo lineal y desarrollista, sino en la de una "heterogeneidad multitemporal" (García Canclini, Culturas híbridas). ${ }^{1}$ Temporalidades en las que habría que distinguir el actuar de

1 Hugo Fazio, siguiendo a Braudel, analiza la globalización en el entendimiento de tres duraciones del tiempo: la historia casi inmóvil, la historia lenta y el tiempo corto: "Si concebimos el fenómeno en una perspectiva de larga duración, lo que comúnmente denominamos globalización no sería otra cosa que una coyuntura en la que se aceleran, amplían e intensifican determinados procesos estructurales. $\mathrm{Si}$ privilegiamos la mediana duración, centramos nuestra atención en la coyuntura en el potencial transformador del proceso para alterar y rediseñar las estructuras del capitalismo. En este sentido, con la globalización no sólo se habría acabado la guerra fría, sino todo el andamiaje económico, político e institucional de la época moderna. Por último, un análisis en términos de corta duración, redimensiona las situaciones inmediatas que caracterizan nuestra historia presente y los agentes interesados en acelerar y conducir este cambio" (25). 
las élites gobernantes -en especial las que se originaron del bucle modernidad/colonialidad- del actuar de las poblaciones subalternizadas o colonizadas. Élites que persisten en disociar lo cultural de los otros componentes condicionantes de la modernidad, como son lo social, lo político y lo ambiental. Entre estos elementos -como bien lo desarrolla Bolívar Echeverría (Crítica de la modernidad) - la democracia es constituyente, y a ella se le exige, aun más en la posmodernidad, la inclusión de las minorías.

Desde esta última perspectiva de la globalización, la definición de la estética deja de estar ligada y limitada a la "alta cultura" y se expande a la experiencia cultural en general. Las valoraciones estéticas dejan de depender de cuán entrenada tenga uno la mirada, y quedan ligadas a múltiples factores, como la complicidad del receptor con el artista (García Canclini citado en Moxey 33) lo cual, en términos de Jorge Dubatti (Una filosofía del teatro), gestaría una experiencia convivial.

Esta última concepción nos lleva a caracterizar a la globalización como la posibilidad de reconstrucción total de las identidades y jerarquías sociales, aunque estructuralmente se manifieste en el desarrollo, expansión y hegemonía del capitalismo, donde el individuo es entendido más allá de su ubicación en tal o cual grupo social. Desde el entendido neoliberal, la globalización se caracterizan por las " $[\mathrm{t}$ ransformaciones que están teniendo lugar en la organización espacial del poder, la cambiante naturaleza de la comunicación, la difusión y aceleración del cambio técnico, la expansión del desarrollo económico capitalista, la extensión de las instituciones de la gobernanza global" (Held y McGrew 138).

Creemos que, en estas condiciones, el devenir de la cultura local, regional y nacional implicaría la generación de nuevas formas -integradas o no- de identidades alejadas de lo monocultural y tradicional. Por lo mismo, se trataría de un terreno propicio para el desarrollo de la interculturalidad, la cual es una condición que se exige desde y por las oleadas migratorias a escala mundial. De ella se derivan diversas expresiones culturales -la mixtura culinaria sería un ejemplo-, que están presentando niveles significativos de inclusión.

En "La Modernidad múltiple", Bolívar Echeverría precisa el motivo por el cual la modernidad, y por extensión la globalización, es una preocupación teórica para los académicos de Latinoamérica: la democracia, sistema político que, en la historia latinoamericana del siglo xx, enfrentó a una oligarquía que, como clase asentada en el poder, imposibilitó la realización tanto de su proyecto como del socialista y, más aún, del de la revolución (un fenómeno que García Canclini [Culturas híbridas] califica como "modernismo sin modernización"). Echeverría reseña la vía de "sustitución de identidad"

2 En Crítica de la modernidad capitalista se precisa que la ponencia de Echeverría se realizó en la Universidad Loyola de Nueva Orleans, en 2001 (177-188). 
por la que Latinoamérica ha procurado pasar de su realidad premoderna a la aspirada modernidad; tránsito intentado vía mímesis, entendiéndose ésta como la imitación de naciones que sí son modernas (entre las que destacan la francesa, la inglesa y, principalmente, la norteamericana).

En el terreno de lo teatral, esta vía mimética ha tenido que ver con puestas en escena de vodeviles, comedias inglesas, autores del absurdo, etcétera. En el caso peruano, ha constituido una estrategia de política cultural que fue reemplazando, progresivamente, la estética castellana por la francesa; luego, por la inglesa, durante aproximadamente dos siglos. No obstante, en el campo de las expresiones dramáticas populares, la mímesis no ha sido solamente imitación acrítica, sino también una estrategia político-estética para alcanzar a ser incluidos -o cuando menos representados- en la escena local. Creemos que el componente mimético no ha fungido solamente como una asimilación enajenante, sino que ha dado lugar también a complejos procesos de negociación para visibilizar las presencias locales o regionales valiéndose de las posibilidades que otorga el ser sujetos globales.

Ya que hemos hablado de modernidad, tenemos que aludir a dos de sus rasgos determinantes: "Una tendencia hacia el comportamiento igualitario" en la vida social, y la internalización social de una "ética de auto-sometimiento productivista" (Echeverría, Crítica de la modernidad 180). Rasgos que, en Latinoamérica, no se han reproducido en forma plena, pues las brechas económicas entre ricos y pobres son abismales, y muchos de los que son ricos no lo son por su espíritu capitalista y moderno (Max Weber, La ética protestante) -entiéndase, productivista-, sino por ser herederos de un legado simbólico, privilegiado por el poder colonial (como pueden ser el color blanco de piel, ciertos apellidos -cuanto más extranjeros y europeos, mejor-, el uso de ciertos idiomas -de preferencia inglés, francés o alemán, aunque el español o portugués resultan suficientes-, etcétera).

\section{La comunidad memoriza su legado al desfilar, danzar, representar...}

Compartimos con Ráez la idea de entender a las festividades tradicionales o locales como eventos abiertos y en constante transformación (6). Una de estas festividades es el desfile en todas sus variantes (cívico, militar, folclórico y religioso). En Yanamarca, Jauja, cada una de las comunidades participantes del desfile presentan una delegación integrada por una banda musical, un agrupamiento militarizado conformado por la tradicional "Tropa de Cáceres" y un batallón de las actuales Fuerzas Armadas. Al final, su compañía dancística (cultural o barrial) ofrece un "carro alegórico" o "cuadro dramático", en el que 
se dramatiza un referente textual que puede ser mítico (generalmente de procedencia bíblica) o de la historia mundial más reciente. ${ }^{3}$

Estos desfiles dramáticos son una herencia. Los incas -como lo reseña Garcilaso de la Vega (Comentarios reales) - la venían practicando en el llamado Inti Raymi, que perdura hasta el día de hoy. Los curacas, o gobernadores de las naciones sometidas al imperio cuzqueño, desfilaban durante esta festividad frente al soberano, acompañados de su séquito. Dentro de este último estaban los encargados de mostrar las danzas, mascaradas e invenciones de cada lugar. ${ }^{4}$

Con la llegada de los españoles, ingresaron también la tradición y las prácticas dramáticas europeas, entre ellas el corso alegórico, que consistía en la presentación de escenas relacionadas a personajes y sucesos históricos tanto de Europa como de América. Desde un principio, la realización de estos desfiles ha estado asociada a festividades religiosas o estatales. En la actualidad, se vinculan también con actos celebratorios institucionales, siendo los más comunes los escolares.

Durante la Colonia, las comparsas religiosas o monárquicas se realizaban por lo general en la ciudad. Su mismo lugar de realización implicaba procesos complejos de negociación política entre ciudadanos que invertían para ser parte de la fiesta. Los habitantes de villas o pueblos lejanos tenían que asegurar su estadía en la ciudad, sufragar los gastos del desplazamiento, hospedaje, etcétera. Asegurar la participación en la fiesta implicaba obtener un lugar en el sistema central de representación. El centralismo generador de subalternidad, tiene así sus raíces en la Colonia, pues quien se desplaza desde la provincia es quien solicita y pide -frente a quien espera, escucha y concede-. Los gobernantes, habitantes de la gran ciudad, evidencian su poder al justificar la centralidad de su posición y, para acrecentar su imagen, invierten en el embellecimiento y modernización de su ciudad. La hacen imponente, solemne, adorable, compleja y atractiva.

Este proceso organiza la mirada del subalterno mediante ciertos gestos de indiferenciación que acortan las distancias para darle la mano, lavarle los pies, u otros ademanes de este tipo que denotan la vulnerabilidad del poder, aunque se presentan disimuladamente como si refirieran a la humildad y benevolencia del mismo. Es por ello que son invitadas las poblaciones o grupos más vulnerables provenientes de los lugares más alejados (por

3 Desfile alegórico que se realiza los jueves y viernes santos de todos los años. Festividad también conocida como "La Magtada de Cáceres".

4 Sánchez Sánchez (18) habla sobre la ceremonia prehispánica de El Dorado, que era una procesión o desfile similar a la narrada por el Inca Garcilaso, y se daba con motivos que el poder generaba. Para el caso colombiano, se habla de la toma de posesión del cacique de Guatavita y, según la crónica de Fray Pedro Simón, continuó por muchos años después de conquistado el reino. 
ejemplo, los nativos), con lo que se logra exhibir la vastedad de la nación y, al mismo tiempo, la actitud paternal de los gobernantes, que atiende y convoca al centro incluso a los que han decidido conservarse en sus costumbres ancestrales.

Todo desfile de danzas (histórico, militar, etcétera) implica el desplazamiento de un conjunto estructurado y jerarquizado de agentes culturales, sociales y políticos; por lo mismo, sirve como agencia festiva para afirmar el poder o estar cerca de éste. El poder de la mirada se articula en el espectador, cuyo punto de vista, educado o calificado para evaluar, aprueba o desaprueba el divertimento ofrecido (siendo los principales espectadores el rey, virrey, presidente, etcétera).

Desde que se crearon los sistemas de divulgación informativa en vivo (en especial los televisivos), capaces de alcanzar a numerosos y distantes conglomerados poblacionales, se ha potencializado el ejercicio del poder articulado en el espectador, quien a su vez tiene la posibilidad de ser visto en vivo por multitudes anónimas. En ese sentido, la participación en el desfile es la consumación de un largo proceso de negociación (deportiva, política, militar, cultural) para estar en la escena y ser reconocido, identificado, destacado, honrado u homenajeado.

En las paradas militares nacionales, la mirada se concentra en la figura del presidente de la República. Todo se planifica para que sea él quien primero se desplace por el sendero del reconocimiento, para luego asumir su ubicación como espectador preferencial. La tecnología de multipantallas consolida la hegemonía del gobernante, enfocando una de ellas en las acciones contemplativas del presidente. La soberanía del gobernante sucede por el dominio que éste tiene al ser capaz de ver y ser visto: él dirige el acto de ver o contemplar, al mismo tiempo que es admirado y visto. Los espectadores constatamos que él o ella tiene el poder de ver, controlar, juzgar, por lo que estamos pendientes de su justa aprobación o sanción ante el espectáculo que observa.

En el desfile popular de Yanamarca -según Ráez- la escenificación procura la simulación dramatizada de un acontecimiento, personaje o idea, ya sea para recordarlo, transformarlo o incluirlo en el conjunto social (29). En el proceso de participación de la fiesta (y dentro de ella, de la ejecución de la expresión dramática folclórica) no nos encontramos ante actores formados de oficio, sino ante pobladores que asumen el rol del personaje que su institución les asigna, como parte del compromiso con la repetición del rito. Este rasgo del enfoque performativo asumido por las expresiones dramáticas folclóricas resulta fundamental, pues permite entender que, junto con los sujetos que desfilan danzando, marchando o actuando, desfilan también sus propios intereses políticos, sociales o culturales. El desfile alegórico se entiende, así, como un mecanismo y un terreno para la negociación de representación estética y política.

En el siguiente apartado analizaremos la actualidad o vigencia de este mecanismo para negociar la inclusión. No obstante, resulta pertinente precisar que la de los Camilles no 
es, propiamente hablando, una danza que contenga personajes definidos a través del vestuario o de una coreografía con pasos establecidos. Se trata más bien de una comparsa o un pasacalle ejecutado por bailantes que -al ritmo de melodías folclóricas del distrito de Sapallanga - se abren paso entre la multitud, atraída por su desvergonzado arrojo. Eduardo Vila (citado en un documental dirigido por Laura Camposano) reseña que esta comparsa se derivó del rol que desempeñaba el Chuto, quien en danzas como la Chonguinada o la Tunantada se encargaba de abrir el campo para que chonguinos o tunantes pudieran danzar con comodidad. Este rol de romper los cercos, abrir senderos o proyectar un espacio, es crucial para comprender el sentido transgresor de los Camilles, pues detrás de ellos no hay sujetos arquetípicamente hegemónicos. Abren un espacio para que lo llene la fantasía, la risa, la parodia, un espacio en el que lo fundamental es la mirada del espectador que acude no para observar la conservación de la tradición, sino para celebrar la inclusión de los nuevos sujetos representados y reírse, burlarse o identificarse con ellos.

Entender la repetición del rito como la conservación original de las tradiciones, pone en tensión los riesgos que presenta la innovación de la escena, no siempre aceptada por el público. Una nueva melodía, un nuevo guiño en el vestuario o en el maquillaje, un nuevo paso en la coreografía, una nueva danza en el corso, asumen el riesgo de ser rechazados. Los Camilles, por lo pronto, han conseguido la condescendiente complicidad de su público.

\section{Te integro, pero conserva tu lugar}

Los desfiles militares, dancísticos, dramáticos y alegóricos cumplen la función neocolonial de demarcar los límites que cada grupo, institución, empresa o comunidad tiene. Las posiciones más importantes resultan ser las extremas, esto es, la primera o la última. Un elemento estético apreciado por el público en el desfile es la sincronización tanto del desplazamiento como de los movimientos de cada actor.

Luis Millones, en su análisis del teatro andino, reseña la participación de actores "naturales" en un desfile de 1725, caracterizando a los personajes del imperio inca. Desde Manco Capac hasta Guascar desfilaron en aquella celebración -con motivo de la proclamación de Luis I- "cantando y recitando lemas y versos que ensalzaban su pasado y su lealtad al rey de España" (Millones citado en Ráez 18). El autor detalla que los actores eran jefes étnicos.

A partir de esta reseña, podemos comprender el sentido que tenía el ser incluido en el programa del desfile colonial: se trataba de un mecanismo que contemporaneizaba el lugar que un cuerpo social (para el caso, el de las élites indígenas) ocupaba en el conjunto social 
después de la conquista. En tal sentido, la participación en el corso implicaba alcanzar el estatus de reconocimiento que le permitía a cada autoridad local, en lo fáctico, participar en la vida política de la sociedad colonial, conservando por supuesto su lugar subalterno.

José Antonio Rodríguez ("Garcilaso y el teatro") explica la notable habilidad argumentativa del Inca Garcilaso para enmarcar lo que él llama "tragedias y comedias incas", en procesos de aprendizaje canalizados por los amautas, con el objetivo de consolidar valores morales y religiosos. El énfasis de Garcilaso en el uso didáctico del teatro por parte de los incas le permite vincularlo a la labor que cumplían los jesuitas en su tiempo, quienes, al igual que los amautas del pasado prehispánico, "han compuesto comedias para que los representen los indios" (Rodríguez 270). Si seguimos la concepción garcilasista de los teatros, tanto del inca como del colonial, y con éstos el del corso, comprendemos su función didáctica para establecer delimitaciones -entiéndase como educar- respecto a los lugares que debían ocupar conquistadores y conquistados a la hora de participar en las celebraciones religiosas o monárquicas.

Históricamente, esta estrategia de participación política desde lo teatral fue suprimida para las poblaciones indígenas, como sanción al respaldo dado a Túpac Amaru. En la sentencia dada por José Antonio de Areche se lee: “También celarán los ministros corregidores, que no se representen en ningún pueblo de sus respectivas provincias comedias, $u$ otras funciones públicas [se entiende que entre dichas "funciones públicas" se encontraban los desfiles alegóricos], de las que suelen usar los indios para memoria de sus dichos antiguos incas" (párrafo 3). La sentencia también prohibía el uso de las trompetas indígenas llamados pututos (caracoles marinos de sonido lúgubre con que anunciaban el duelo), el uso de vestidos negros que los indígenas "arrastran en algunas provincias, como recuerdos de sus difuntos monarcas, y del tiempo de la conquista, que ellos tienen por fatal, y nosotros por feliz, pues se unieron al gremio de la Iglesia católica, y a la amabilísima y dulcísima dominación de nuestros reyes" (ibídem).

Las consecuencias de estas prohibiciones -a las que habría que añadir la del uso de la lengua indígena- fracturaron las expresiones culturales de resistencia, aquella hermenéutica del sentido que tuvo la conquista y dominio hispano desde la episteme de los vencidos. En este punto, sigo la propuesta de Miguel León Portilla, quien recoge las "relaciones" orales, escriturales y pictográficas (a las que habría que sumar las performativas) de los vencidos (Visión de los vencidos). Los sujetos subalternizados por la maquinaria colonial pasaron por un largo proceso de reapropiación de los códigos culturales del dominante, para reasumir su resistente existencia y su condición disidente. Entre los códigos de los que se apropiaron están los instrumentos musicales de cuerda, vestir polleras y trajes a la usanza española y, sobre todo, negociar su participación en el desfile o corso alegórico (no en el modo como fue utilizado por el imperio inca, sino en sus espe- 
cificidades coloniales: carnavalesco y heterogéneo). Esta adopción les permitió, incluso en el periodo de instalación de los criollos republicanos -y aún lo hace en las esferas de decisión política-, crear un espacio celebratorio de representación y reconocimiento de nuevos grupos sociales, nuevos sucesos, nuevos saberes, etcétera. Pero siempre bajo la impronta colonial: te incluyo pero mantén tu distancia y lugar en el desfile, y haz lo mismo concluida la fiesta.

La posibilidad de ser incluido o incluir en el desfile, como vemos, tiene la función de articular socialmente a los diferentes grupos de una determinada comunidad, pudiendo ser algunos de éstos originarios del lugar y otros -la mayoría - foráneos, aunque ya asentados en el mismo espacio geográfico. En lo fáctico, algunos de estos grupos habitan las periferias de la ciudad, pero en cuanto son convocados por la fiesta su inclusión es celebrada. No siempre se trata de grupos que se han territorializado en espacios físicos concretos, sino más bien en los imaginarios locales.

Por ejemplo, en el Valle del Mantaro, uno de estos grupos sociales afincados en el imaginario festivo es el de los negros. Muestra de ello son las llamadas negrerías, como la de los Chacranegros en la localidad de Huaripampa. ${ }^{5}$ Los lugareños celebran con esta danza la abolición de la esclavitud, aunque no todos ellos sean ni desciendan de gente de color. Se trata de una muestra de identificación solidaria con aquellos cuyos derechos fundamentales tardaron en ser reconocidos por el Estado.

Otra danza representativa de la inclusión progresiva -aunque siempre conservadora- es la Tunantada, que ha ido incorporando cada vez más personajes al desfile. En lo fáctico, sus rasgos y posiciones económicas y culturales han sido asimiladas por la población. A los clásicos Tunante, Chuto o Huatrila, y a la Kutuncha o Wankita, se han ido sumando paulatinamente cerca de 11 personajes más: Jaujina, Argentino, Boliviano o Jamille, Indio, María Pichana y su pareja el Auquis, la Cuzqueña o Nusta, el Chuncho o Anti, la Sicaina, y el Doctor o Abogado. ${ }^{6}$ El Chuto y Argentino son los encargados de acondicionar un espacio en el que el Tunante y los demás acompañantes puedan danzar con soltura. La forma de delimitar las jerarquías tiene que ver con el número y la posición durante la ejecución del pasacalle. Si bien los que danzan como huatrilas o chutos pueden ser numerosos, su posición siempre es periférica, ya sea en la vanguardia o en los laterales (ubicación que comparten con los personajes recientemente

5 Representación que se realiza los días 8 de enero de cada año, en paralelo a la Tunantada. En esa localidad, esta última danza se desarrolla del 6 al 9 de enero; en Jauja, se hace el 20 de enero.

6 Benilda Hidalgo Bravo e Idayna Ceras (2017) han analizado los parlamentos de cada uno de los personajes de esta danza. Un guión que, suponemos, es el rezago de una danza dramática que, con el paso del tiempo, se ha replanteado, dejando de lado el texto y conservando, en la actualidad, sólo algunas onomatopeyas. 
INVESTIGACIÓNTEATRAL

Revista de artes escénicas y performatividad

Vol. 10, Núm. 16

octubre 2019-marzo 2020
Teatralización popular en el Valle del Mantaro, Perú: negociando la inclusión

Jorge Luis Yangali Vargas

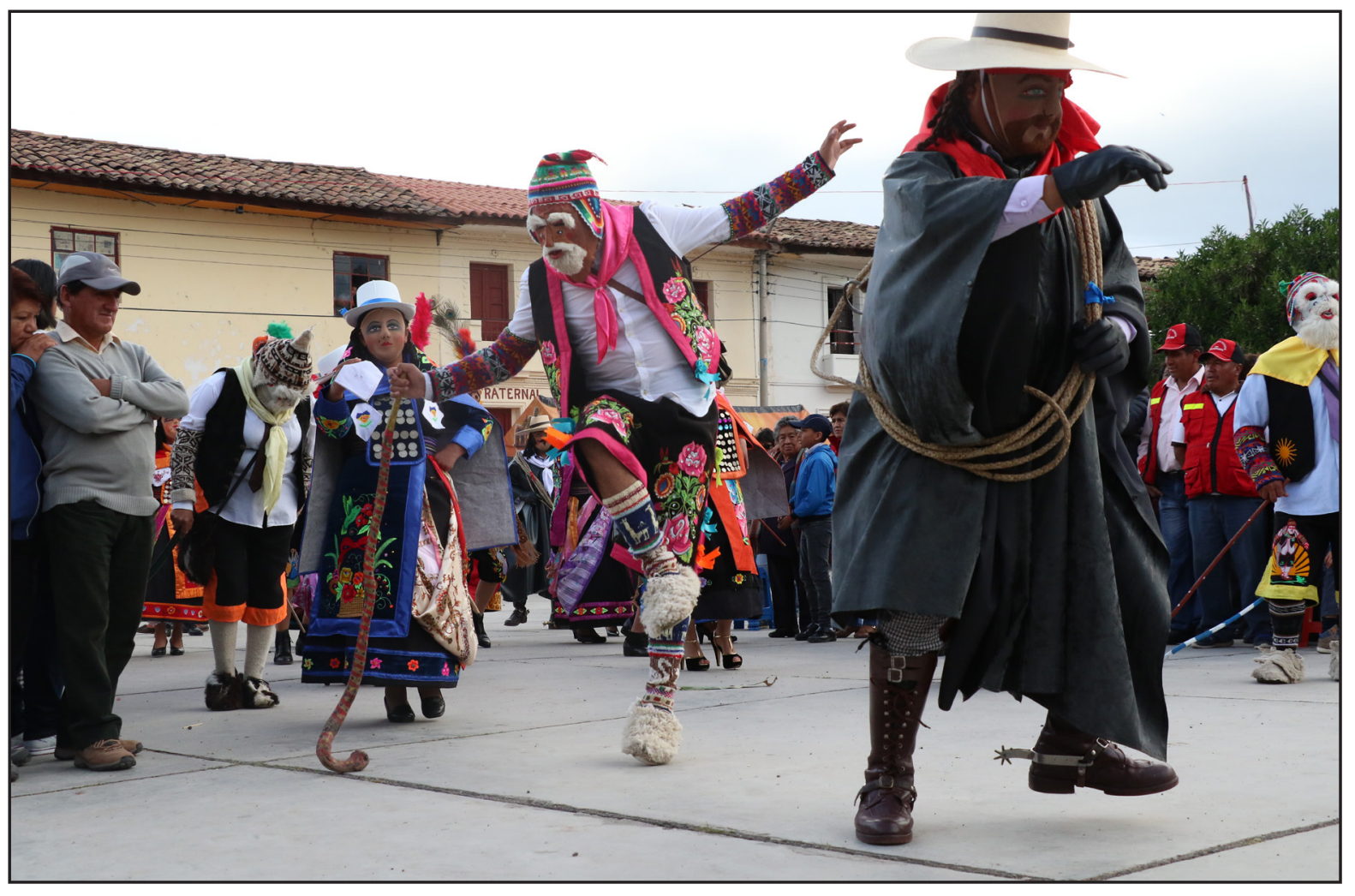

Argentino y chutos abriendo el espacio para que luego ingresen los tunantes. Huaripampa, Jauja, enero de 2019. Fotografía de Jorge Yangali.

incorporados, por lo general encarnados por pocos danzantes). El lugar central y los que son encarnados por más danzantes corresponde a los personajes femeninos y, por supuesto, a los tunantes.

\section{Escenificando la historia o la hermenéutica popular del trauma}

Uno de los tipos de desfile más ejecutados en el Valle del Mantaro es el corso histórico, en el que se representa la memoria popular de algún suceso que ha dejado su impronta. Uno de ellos es el derivado escénico de los llamados dramas de conquista (Manuel Ráez, "Imaginario global"; Cornejo Polar, Escribir en al aire; Víctor Domínguez, Danzas e identidad nacional). Este corso dramático representa principalmente la captura del Inca Atahualpa. Es significativo, por ejemplo, el titulado La toma del Inca o 
Apu Inca de Sapallanga que se lleva a cabo en la misma población; durante la misma festividad, en la que acontece la danza de los Camilles, también se presenta la celebración de Mamacha Cocharcas (Virgen de las Mercedes). En escena se representa la caída del imperio, la captura y muerte del Inca Atahualpa, así como el consecuente triunfo de los españoles. La danza finaliza con la cristianización y matrimonio de las mujeres del Inca con los ibéricos. En este baile se tiene al sacerdote como la figura que consolida y valida esta unión (personaje que será resignificado en los Camilles al parodiar y validar una ceremonia de bodas entre dos sujetos, donde uno de ellos se ha travestido para la ocasión).

Los triunfantes criollos del siglo XIX no fomentaron las expresiones dramáticas heredadas de la Colonia. Las reemplazaron por actividades teatrales de salón. En el caso de los desfiles alegóricos, éstos fueron reemplazados por los desfiles cívico-militares que perduran hasta hoy. Hasta donde hemos investigado, será con motivo de la celebración del primer centenario de la Independencia, en el gobierno de Leguía (1919-1929), ${ }^{7}$ que reaparecerá el desfile alegórico, escogiéndose en aquel entonces a los carnavales como fecha propicia para reanimar este mecanismo de representación.

Como bien observa Ráez, las escenificaciones populares indígenas, despreciadas por las élites criollas, serán retomadas en el siglo xx como consecuencia del influjo del movimiento indigenista y del nacionalismo moderno. El Inti Raymi ${ }^{8}$ cuzqueño, por ejemplo, es vuelto a escenificar en su versión actual desde 1944. Cabe anotar que no fueron los indígenas quienes reanimaron esta dramatización, sino los mistis, ${ }^{9}$ de ahí su carácter oficial. Siguiendo a Rommel Plasencia, podríamos inferir que las élites locales, aprovechando la potencialidad del discurso indigenista en las nuevas condiciones socioeconómicas, se apropiaron de los signos y del mismo indio para constituirse en sus representantes, perpetuando de este modo su dominio local. Plasencia explica el mecanismo de apropiación cultural de parte de los mistis en los siguientes términos: "me apropio del sujeto indio pues lo conozco en la convivencia y luego lo redimo académica y políticamente, pero para ello tengo que hacerlo inexpugnable a mi propia sociedad, para exacerbar su otredad, su interioridad inexplicable" (81).

7 Sobre el análisis del influjo del indigenismo durante el Oncenio de Leguía, véanse los aportes de Wilders Ramírez Trebejo (Representar lo peruano) y el de Ráez.

8 Representación que se realiza el 24 de junio.

9 Rommel Plasencia, en una nota al pie de su artículo "Modernidad y Antimodernidad en los Andes", define al misti como "los llamados también mestizos, blancos, wiracochas, taitas, propietarios, caballeros o vecinos, poseen distintos atributos locales, pero todos son definidos en oposición a los comuneros, campesinos o indígenas" (76). 
INVESTIGACIÓNTEATRAL

Vol. 10, Núm. 16

octubre 2019-marzo 2020
Teatralización popular en el Valle del

Mantaro, Perú: negociando la inclusión

Jorge Luis Yangali Vargas

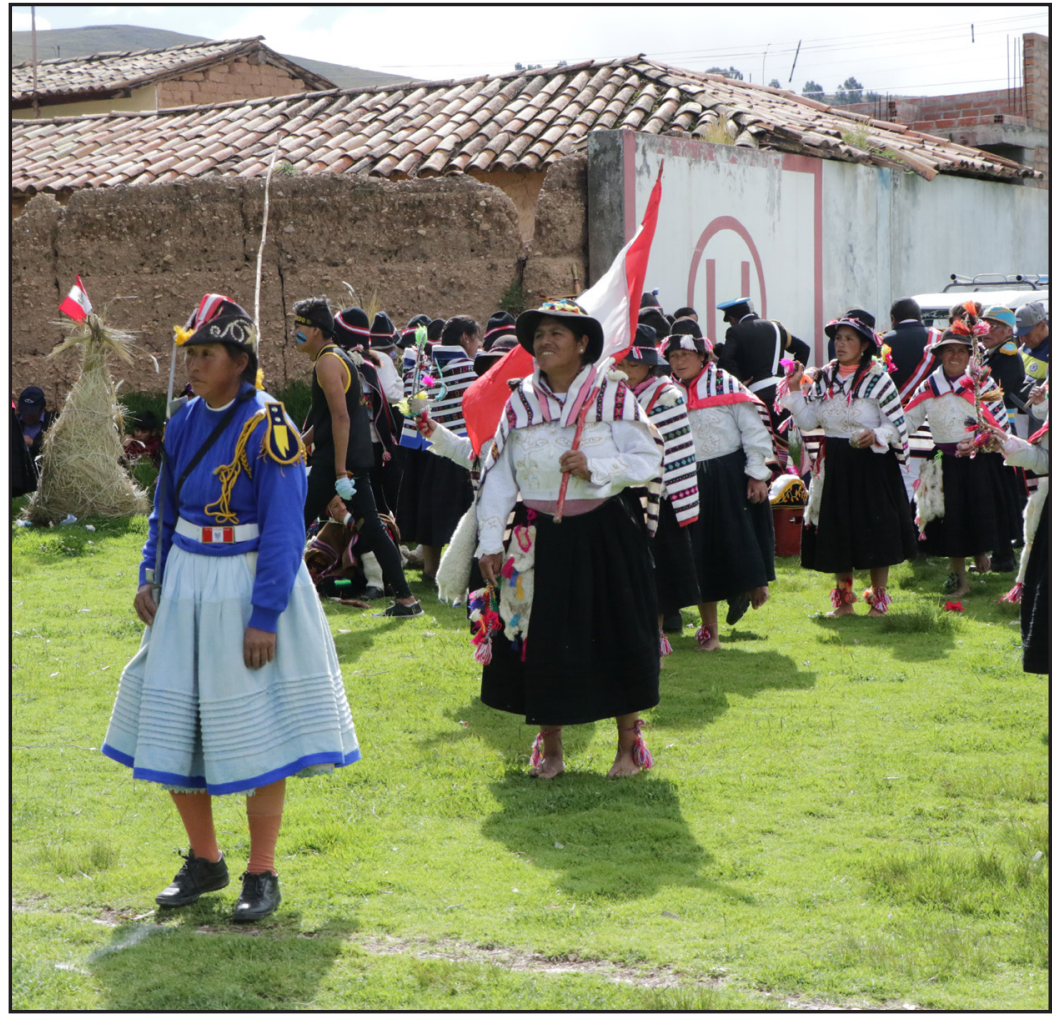

Rabonas de la Tropa de Cáceres, dirigida por una Mariscala en Marco, Jauja, abril de 2019.

Fotografía de Jorge Yangali.

Este retorno de la mirada sobre las poblaciones indígena y mestiza en el primer centenario no es casual ni un acto benevolente de la élite gobernante. Algunas de las danzas locales del Valle del Mantaro nos permiten argumentar que ambos movimientos, el indigenista y el moderno, se vieron provocados y respaldados por la decidida y victoriosa participación militar de indígenas y mestizos del centro peruano durante la guerra con Chile, que contrastó con el traicionero y cobarde accionar de la élite criolla limeña, como bien será ensayado por Manuel Gonzáles Prada (Pájinas libres). Incluimos, entre esas escenificaciones, a los Avelinos, ${ }^{10}$ en alusión a Andrés Avelino Cáceres, el Brujo de los Andes, así como La Maqtada de Cáceres o Tropa de Cáceres, entre otras expresiones artísticas del Valle del Mantaro. En el pueblo de Marco, la participación arrojada y activa de las mujeres en dicho acontecimiento bélico ha permitido la configuración de una Mariscala, misma que está al mando de una tropa conformada íntegramente por damas marqueñas.

10 Su representación acontece del 16 de agosto al 30 de septiembre en la localidad de San Jerónimo en el Valle del Mantaro. 
En este nuevo siglo xxI, las representaciones dramáticas sobre la guerra del Pacífico se han multiplicado, siendo las más recientes, en el Valle del Mantaro, las masivas escenificaciones de las batallas "en vivo". Resaltan las que se realizan en los distritos de Pucará y Concepción el 9 de julio, así como la de Chupaca del 19 de abril. Versiones triunfantes las dos primeras, mientras que, en la tercera, si bien se pierde la batalla, la victoria radica en no haber cedido cobardemente a la deshonra exigida por los chilenos, pues éstos exigían como demostración de rendición la entrega de una dote de mujeres vírgenes. Escenificaciones que se ejecutan in situ, en parques y terrenos abiertos a la representación.

Todas estas expresiones dramáticas populares constituyen un esfuerzo colectivo mnemotécnico por conservar la hermenéutica local (en paralelo a la historiografía oficial), ante dos de las experiencias históricas traumáticas para el Perú, como lo fueron la conquista y la guerra con Chile. Respecto a éstas, se enfatiza la participación activa de pobladores anónimos, tanto varones como mujeres. Los Camilles también tematizan dicho anonimato al vestir máscaras blancas o rosadas y al desfilar sin tener un lugar definido.

No obstante, en este punto cabe preguntarse por el periodo histórico y el "trauma" que los Camilles buscarían escenificar. Durante la festividad de Mamacha Cocharcas de Sapallanga, las danzas del Apu Inca, la Chonguinada y la Negrería tienen que ver con periodos y sujetos específicos de un pasado delimitado. Los Camilles, en cambio, escenifican un presente globalizado, no traumático y siempre abierto, donde tienen cabida faraones, israelitas, soldados romanos, arlequines, obispos, políticos, travestis, académicos, cantantes folclóricas, novias, deportistas, etcétera.

\section{Al carnavalizar la fiesta patronal nos mezclamos todos}

El carnaval es una de las fechas más celebradas en gran parte de América (hispana y lusitana) y en la que destacan los corsos alegóricos. Corso carnavalesco que conlleva a participar en el goce del reconocimiento público. Aprovechando el mecanismo colonial del desfile alegórico, también se representan -en algunos casos por única vez y en otras para perpetuarse- danzas de localidades o naciones vecinas. En el Valle del Mantaro, por ejemplo, las danzas puneñas y bolivianas llegaron para instalarse, como ya instalados están ahí también los migrantes aymaras.

El festival alegórico del carnaval del siglo xx ha incorporado dos momentos que se replican en todos los corsos: el paseo de la elegida reina de belleza del carnaval y la lectura del bando (por lo general satírico) del Ño Carnavalón o Rey Momo, ${ }^{11}$ cuyo discurso sirve para

11 En algunas localidades de Jauja, provincia que forma parte del Valle del Mantaro, el corso alegórico adquiere el nombre de Calistrada; según Ráez, el término se deriva del rey Calixto o Rey Momo (28). 
realizar críticas mordaces y jocosas frente al accionar de personajes representativos de los ámbitos local, nacional y -últimamente- global.

Pero estos modernos desfiles alegóricos no son sólo carnavalescos. Más bien son convocatorias a los actos celebratorios cívicos e institucionales. De ahí que no necesariamente tienen que darse durante el calendario festivo del carnaval, sino que, más bien, se representan para iniciar y convocar a la población interesada en asistir a los actos conmemorativos del municipio, la escuela, la empresa, etcétera.

En otras palabras, el desfile alegórico es un mecanismo estético de afirmación de identidad y, al mismo tiempo, de posibilidades de inclusión social que hay que celebrar. Un ejemplo de esto son los Camilles de Miluchaca (uno de los últimos grupos dancísticos integrados a la festividad de Mamacha Cocharcas), en los que la mayor atracción son los numerosos sujetos travestidos. No obstante, sería muy apresurado señalar que se trata de una celebración festiva de la inclusión fáctica de los travestis en la comunidad. ${ }^{12}$

De acuerdo a Beatriz Rizk, la tensión entre la globalización y la singularidad local, en especial la de América Latina, "ha producido discursos que si, por un lado, han señalado lo tendencial y contradictorio de toda identidad dada por hecha, por otro, se ha ido insertando una cultura 'otra', con símbolos y modelos que vienen de afuera, con que se ha tensionado lo propio, pues es obvio que las utopías cotidianas ya no se forjan en el espacio geopolítico tradicional ni en sus respectivas identidades culturales" (36).

El travestismo en las danzas andinas se registra en múltiples representaciones folclóricas. De acuerdo con Iván Villanueva ("Yo soy una drag queen"), en su análisis del dragqueenismo en Lima, el travestismo en el Perú también forma parte de la cultura popular, en especial de aquella que es propagada por los medios masivos como la televisión. ${ }^{13} \mathrm{El}$ fenómeno involucra en general a hombres que visten de mujer en determinados contextos, sin que necesariamente sean travestis como tales.

El travestismo andino está estrechamente asociado con lo festivo, lo chistoso. En aquel que caracteriza a los Camilles, encontramos a personajes como la escolar, la drag queen (hombre homosexual que actúa de manera ruda o "masculina"), la enfermera, la cantante folclórica, etcétera. El público de los Camilles no es predominantemente gay ni lésbico, sino

12 Celebración en honor de la Virgen que se inicia el 7 de septiembre y se prolonga por dos semanas en la localidad de Sapallanga. Los Camilles participan de ella entre el 16 y el 19 de septiembre.

13 Entre algunas de las interpretaciones sobresalientes del travestismo, tenemos a la Chola Eduvijes (representado por Guillermo Rossini), la Chola Chabuca (por Ernesto Pimentel), la paisana Jacinta (por Jorge Benavides). Cuentan también las distintas cholas representadas por los cómicos ambulantes. Entre las representaciones de mujeres no andinas o cholas, tenemos a Juana (mujer de la Amazonía), por Edwin Sierra, y la tía Bombelé (afroperuana), por Martín Farfán. 
popular. El objetivo inmediato es el entretenimiento de un pueblo devoto, que tolera estas actuaciones. No son artistas profesionales ni viven de ello. Son sujetos que suspenden el tiempo laboral y sus masculinidades durante los días que dura su celebración religiosa. Su fiesta hiperboliza lo "desviado", lo "enfermo", lo "drogado", etcétera (cabe aclarar que no empleo estos términos de modo peyorativo). Se trata de un acto de fe que, además de parodiar a la historia global, traviste la hegemonía de la ceremonia religiosa. Se trata de un reality show popular, en el que se presenta cómicamente la "identidad" de los sujetos representativos del imaginario transmediático: travestis, el Chapulín Colorado, sujetos religiosos (sacerdote, israelita), etcétera.

Los Camilles han llevado la noción de inclusión hasta sus límites. En su comparsa desfilan, danzan, se casan y comulgan -en tono folclórico y popular- figuras de fantasía (piratas, el Chapulín Colorado, los Teletubbies) respecto a los que no tiene el menor sentido pensar en su inclusión fáctica. Se desafían de este modo los cimientos mismos de la representación democrática, que no puede incluir minorías inexistentes y que, sin embargo, presenta sujetos que sí existen detrás del disfraz. Siguiendo la idea de Keith Moxey ("Estética de la cultura"), los Camilles estarían entre aquellas prácticas artísticas que, más que normalizar universales mass-mediáticos, problematizan de raíz uno de los valores que sostienen al sistema global: la democracia, que sólo sería viable si se la parodia.

\section{Para gozar hay que pagar}

Las expresiones populares son sostenidas anualmente mediante el sistema del "encargo" y "compromiso". Este encargo de la fiesta se asigna a la junta directiva de la asociación, barrio o comunidad en turno y, de modo individual, se insta a cada participante de la fiesta a que asuma un "compromiso" para el siguiente año.

Todos los desfiles alegóricos hasta aquí mencionados son eventos públicos y gratuitos. No obstante, para hacerlos sostenibles, muchos han ingresado también a un sistema de consumo y asistencia privados. Los costos de ingreso a los recintos -puesto que se trata de eventos masivos- no son excesivos. Al interior de los locales, los diferentes puntos de venta de comida y bebida han sido rentados a terceros (vivanderos) por los organizadores, obteniéndose de ese modo ingresos para afrontar los gastos de la fiesta. En otras palabras, el gozo popular se sostiene administrando en forma exclusiva y privada la ingesta de alcohol y comida. La participación de cada compañía, asociación, comunidad o empresa -y por ende el alquiler de vestuario, maquillaje, etcétera- es asumido por las mismas instituciones, quienes tienen la posibilidad de recuperar parcialmente lo invertido cuando los organizadores -generalmente las alcaldías distritales o provincia- 
les- establecen premios monetarios para las mejores interpretaciones y construcciones de las alegorías. Aunque el premio monetario parezca merecer el esfuerzo, no supera a la inversión realizada (siendo principalmente su función la de motivar a asumir riesgos e innovaciones en cada montaje escénico).

En el terreno de la sustentación de la fiesta, cabe recordar la pregunta que formula Michael Rustin, recordada por Zygmunt Bauman, ¿qué hay de malo en la felicidad? y, sobre todo, aquella observación que Rustin hace al respecto: las sociedades como las nuestras son percibidas como notoriamente prósperas, pero no está claro si son más felices (6). Si bien el contexto socioeconómico analizado por Rustin y Bauman difiere del nuestro, las categorías que ellos emplean pueden quedar reconfiguradas -aun conservando su teleología ritualmente primigenia- con respecto al goce en las representaciones por nosotros analizadas.

En las asociaciones culturales que han heredado los valores culturales tradicionales (como la Sociedad Cultural de los Camilles de Miluchaca), el componente económico incrementa potencialmente el nivel de felicidad. De acuerdo con Jorge Yamamoto, Huancayo, localidad integrada al Valle del Mantaro en la que se ubica el pueblo de Miluchaca, es una de las ciudades con mayor índice de felicidad, debido a que sus habitantes, además de cooperar entre sí, poseen "los valores más altos, sentido de trabajo y espacio para la recreación. Los huancaínos son los menos envidiosos y maleteros del Perú. [El huancaíno] es muy chambeador y muy leal a su comunidad" ("Huancayo", entrevista). ${ }^{14}$

En tal sentido, la participación en la fiesta vendría a ser la expresión sublime que compensa el esfuerzo laboral. De ahí que al encargado le sea necesario exhibir, ante los celebrantes, su desprendimiento y derroche de plusvalía acumulada. Es indispensable que exhiba y declare lo feliz que se siente, implicando que, gracias a su crecimiento económico, ha adquirido un estilo o forma de vida que es imaginado como superior al que ha dejado atrás. Un estilo o forma de vida al que sus compueblanos también pueden aspirar, volviéndose eventualmente "superiores" en la medida en que progresen económicamente y lleguen a asumir los cargos más ostentosos en las festividades.

Los integrantes de la Sociedad de Camilles procuran teleológicamente divertir a sus espectadores. A la actitud tolerante de su comunidad, que acepta e incluye a la Sociedad aun en su radical desemejanza con la tradición (al menos durante el tiempo de la fiesta), los Camilles le devuelven momentos de divertimento. Luego de los oficios religiosos, los bailantes se desplazan por las calles del pueblo y arriban al coliseo que se ha erigido tem-

14 En contraste con estos valores, Yamamoto señala que las localidades peruanas más infelices se caracterizan por albergar sociedades de estructuras rígidas, que buscan la conservación de privilegios socioeconómicos y no son capaces de generar nuevos ricos (sino nuevos -y acomplejados- pobres). 
poralmente. Los espectadores realizan un pago de ingreso al recinto. Adentro, los Camilles ofrecen espectáculos paródicos (un partido de fútbol, un torneo pugilístico, la realización de una boda, etcétera). Algunos de estos espectáculos involucran a los espectadores, cuya participación puede llegar a ser premiada con víveres, calzado o bienes de este tipo. El privilegio de entregar los premios recae en el presidente de la Sociedad Cultural, es decir, la persona que ha realizado la mayor inversión para levantar la fiesta.

Una de las pruebas que más atrae es la de los palos encebados, la cual constituye un reto de habilidad, pero, al mismo tiempo, de demostración jerárquica. No importa tanto quién logre llegar a la cúspide y obtener el don de lo alto del palo, sino, sobre todo, quién fue el que colocó o puso el regalo, dando a los subalternos la posibilidad de ascender simbólicamente para obtener aquel bien.

Si bien el goce de la fiesta es perecedero, su satisfacción es perdurable, pues a la celebración le siguen comentarios, agradecimientos, muestras de deferencia, solicitudes de préstamos, etcétera. Se trata de la acumulación subjetiva de un capital simbólico y socio-afectivo, cuyos beneficios son esperados durante un año antes de lograr adquirirse. Las asociaciones culturales exaltan estos beneficios, producidos en el intercambio entre el sacrificio individual y el goce que produce la participación en la fiesta (de ahí que estén justificados un permiso laboral, una intervención médica, etcétera). De igual modo, se incide en la praxis del "milagro" o la "bendición" de la que los bailantes potencialmente se benefician al terminar la fiesta. Se afirma la convicción de que merece la pena realizar el sacrificio; la fiesta impulsa un sacrificio teleológico.

La relación entre felicidad y crecimiento económico también tiene que ver con la cantidad y -últimamente- la calidad del consumo (Bauman 12). De ahí que en el Valle del Mantaro se insista en que la fiesta sea ostentosa e insuperable en cuanto al consumo de alcohol, la opípara ingesta de platos típicos, el número y bullicio de las bandas de músicos y, sobre todo, en lograr el compromiso de atraer un número de bailantes que supere cada vez al del año anterior. En esta lógica de ostentación, se invita a participar a todas aquellas personas que, en el transcurso del año, han alcanzado un nivel de confianza e intimidad como para hacerlos parte de la orgía. Y es desde esta lógica que se suele incluir a los otros: no a todos, sino -reiteramos- a quienes han alcanzado un nivel de empatía y afectación entre los administradores de la fiesta.

Este mecanismo de inclusión y reconocimiento tiene que ver con facultar al otro para que pueda vestir los rasgos de identidad de la agrupación cultural, con sus logos o distintivos. Además de la pertenencia telúrica y, en algunos casos, biológica, la inclusión en estos desfiles se da por la participación y fidelización, no necesariamente con lo religioso, sino con la plusvalía de la fiesta propiamente dicha: el goce de evidenciar la identidad de lo diversamente humano. 
Bauman habla del reciclaje en relación con la "manipulación de la identidad" (16). En los Camilles observamos sujetos variopintos que conservan las marcas de identidad mínimas: máscara (blanca o rosada) y etiqueta en el vestuario, portadas como si se trataran de una insignia escolar. Fuera de estas dos marcas, cada intérprete elige su propio vestuario según sus gustos o el grado de provocación que quiera asumir ante el público. Lo más recurrente es vestir de mujer, mientras que los atuendos de mayor prestigio son los de obispo, juez, etcétera. En esta elección del vestuario juega la sensibilidad de cada quien respecto a su lugar en la historia global: el migrante venezolano, por ejemplo. ${ }^{15}$

A esta construcción de la identidad desde el reciclaje de diversos sujetos provenientes de múltiples contextos populares, se suele imputar críticamente la celebración del simulacro que, de acuerdo a Jean Baudrillard (citado en Bauman 16), se caracteriza por su similitud con las enfermedades psicosomáticas, las cuales "tienden a borrar la distinción entre las cosas como son y las cosas como pretenden ser, entre la realidad y la ilusión, o entre el verdadero estado de la cuestión y su 'simulación". Los Camilles están llamados desafiantemente a no incurrir en este tipo de simulacro.

\section{Conclusiones}

Las manifestaciones posmodernas de luchas por reivindicaciones sociales, o de divulgación de posturas (como la feminista, la ecologista, etcétera), se valen también de las posibilidades que les da esta expresión dramática del desfile alegórico para negociar su representación política y la potencialidad de la inclusión de derechos, interpretando alegóricamente un mal o un bien social en ese contexto.

Una de las discusiones fundamentales en las estéticas de la inclusión tiene que ver con los mecanismos de representación. Si bien en las expresiones populares teatrales del Valle del Mantaro múltiples sujetos (negros, bolivianos, nativos amazónicos o variopintos seres de ficción) son incluidos, no siempre estarán representados todos los grupos y no siempre los incluidos en el desfile representarán fácticamente a los grupos sociales con los que supuestamente se identifican.

El espectador de los Camilles se distancia de lo que tradicionalmente se asocia con las expresiones folclóricas vinculadas a la festividad de Mamacha Cocharcas y, al mismo tiempo, se mantiene vinculado a ella. Los Camilles despojan a la fiesta de su carácter exótico y de postal turística, folclorizan lo universal, liberan a la tradición de una espe-

15 En la festividad del año pasado (2018), debido al éxodo de los venezolanos por Latinoamérica, se les representó/incluyó en los Camilles. 
cificidad esencialista (lo que llamaríamos su identidad original). En el folclore convencional se uniforma lo heterogéneo, mientras que en los Camilles se multiforma -desde el ocultamiento y lo diverso- lo que de hecho es radicalmente heterogéneo. Los sujetos modernos y eurocentrados representados en esta tradición son reconfigurados desde el acto de parodiar lo global.

\section{Fuentes consultadas}

Bauman, Zygmunt. El arte de la vida. De la vida como obra de arte. Traducido por Dolores Udina. Editor digital, www.lectulandia.co/book/el-arte-de-la-vida/, 2008, consultado el 1 de agosto de 2019.

Cornejo Polar, Antonio. Escribir en el aire. Ensayo sobre la heterogeneidad sociocultural en las literaturas andinas. Lima-Berkeley: Celacp/Latinoamérica Editores, 2003.

De Areche, José Antonio. "Sentencia a José Gabriel Tupac-Amaru, su mujer, hijos, y demás reos principales de la sublevación". Blog de Grover Cornejo Yancce, 5 de agosto de 2013 [1781], blog.pucp.edu.pe/blog/conciliacion/2013/08/05/sentencia-a-jos-gabriel-tupac-amaru-su-mujer-hijos-y-dem-s-reos-principales-de-la-sublevaci-n/, consultado el 1 de agosto de 2019.

De la Vega, Garcilaso. Comentarios Reales de los Incas. Lima: Biblioteca Clásicos del Perú, 1985.

De Sousa Santos, Boaventura. Una epistemología del Sur. Traducido por José Guadalupe Gandarilla. Buenos Aires: Clacso/Siglo xxi Editores, 2009.

Domínguez Condezo, Víctor. Danzas e identidad nacional. Lima: Editorial San Marcos, 2003.

Dubatti, Jorge. Una filosofía del teatro. El teatro de los muertos. Lima: AIBAL/ENSAD, 2016.

Echeverría, Bolívar. Crítica de la modernidad capitalista. La Paz: Oxfam/Vicepresidencia del Estado Plurinacional de Bolivia, 2011.

Fazio Vengoa, Hugo. "Una mirada braudeliana a la globalización”. Convergencia, año 7, núm. 21, 2000, pp. 11-47.

García Canclini, Néstor. Culturas híbridas. Estrategias para entrar y salir de la modernidad. Ciudad de México: Editorial Grijalbo, 1989.

Gonzáles Prada, Manuel. Pájinas Libres. [Lima]: Ediciones Peisa, [197-?].

Held, David y Anthony McGrew. Globalización / Antiglobalización. Barcelona: Paidós, 2003.

Hidalgo Bravo, Benilda e Idayna Ceras Pino. Léxico de la tunantada a través de los personajes en Yauyos, Jauja. Tesis de licenciatura en Educación, Universidad Nacional del Centro del Perú, 2017. 
León Portilla, Miguel. Visión de los vencidos. Relaciones indígenas de la conquista. Ciudad de México: unAM, 1989 [1959].

Marshall McLuhan y B. R. Powers. La aldea global. Traducido por Claudia Ferrari. Barcelona: Gedisa, 1995.

Millones Santagadea, Luis. Actores de altura. Ensayos sobre el teatro popular andino. Lima: Horizonte, 1992.

Moxey, Keith. "Estética de la cultura visual en el momento de la globalización". Estudios visuales. Epistemología de la visualidad en la era de la globalización, editado por José Luis Brea. Madrid: Ediciones Akal, 2005, pp. 27-37.

Orellana Valeriano, Simeón. "La Tunantada de Xauxa-Yauyos: chutos y huatrilas". Boletín del Instituto Riva-Agüero, núm. 30, 2003, pp. 345-382.

Orellana Valeriano, Simeón. Mitos y danzas rituales del Valle del Mantaro. Lima: Fondo Editorial del Pedagógico San Marcos, 2007.

Piñero, Gabriela. "Políticas de representación / políticas de inclusión. La reactualización del debate de lo latinoamericano en el arte durante la primera etapa de la globalización (1980-1990)". Anales del Instituto de Investigaciones Estéticas, vol. 36, núm. 104, 2014, pp. 157-186, http://www.analesiie.UNAM.mx/index.php/analesiie/article/view/2519, consultado el 1 de agosto de 2019.

Plasencia Soto, Rommel. "Modernidad y Antimodernidad en los Andes". Inquisiciones / Antropología. Lima: unmsm/Seminario de Historia Rural Andina, 2015, pp. 85-107.

Ráez Retamozo, Manuel Pablo. Imaginario global y creatividad local. Los desfiles dramatizados en el Valle de Yanamarca. Tesis de Magíster en Antropología, Pontificia Universidad Católica del Perú, 2013.

Ramírez Trebejo, Wilders Andrés. Representar lo peruano. Folclore e identidad nacional a partir del estudio de la obra de Rosa Elvira Figueroa (1948-1988). Tesis de Magíster en Antropología, Pontificia Universidad Católica del Perú, 2016.

Rizk, Beatriz J. "La sociedad del espectáculo y la 'estética de lo real' en el teatro latinoamericano contemporáneo". Gestos, núm. 60, 2015, pp. 33-46.

Rodríguez, José Antonio. "Garcilaso y el teatro de los Incas”. Renacimiento mestizo: los 400 años de los Comentarios Reales, editado por José Antonio Mazzotti. Madrid/Frankfurt: Universidad de Navarra/Iberoamericana/Vervuert, 2010, pp. 257- 272.

Romero, Raúl R. Debating the Past: Music, Memory, and Identity in the Andes. Oxford: Oxford University Press, 2001.

Romero, Raúl R. Identidades múltiples: memoria, modernidad y cultura popular en el Valle del Mantaro. Lima: Fondo Editorial del Congreso del Perú, 2004.

Sánchez Sánchez, Carlos Enrique. Las representaciones sociales en la región andina co- 
lombiana: entre las teatralidades, la fiesta, la religión y el mito. Tesis de doctorado, Universidad Pablo de Olavide, 2017.

Toffler, Alvin. La tercera ola. Traducido por Adolfo Martin. Bogotá: Plaza \& Janes, 1980.

Vila, Eduardo. Entrevista. "Camilles de Milichaca [documental]". YouTube, subido por produccionesyerson laura, 28 de diciembre de 2016, www.youtube.com/watch?$\mathrm{v}=9 \mathrm{Kwl}-\mathrm{Q} 4 \mathrm{lfLc}$, consultado el 1 de agosto de 2019.

Vilcapoma, José Carlos. Waylarsh: amor y violencia de carnaval. Lima: Pakarina Ediciones, 1995.

Vilcapoma, José Carlos. "La maqtada de Cáceres: recuerdos de guerra". Cuadernos arguedianos, año 2, núm. 2, 1999, pp. 39-52.

Villanueva Jordán, Iván. "Yo soy una drag queen, no soy cualquier loco. Representaciones del dragqueenismo en Lima, Perú”. Península, vol. 12, núm. 2, 2017, pp. 95-118.

Weber, Max. La ética protestante y el espíritu del capitalismo. Ciudad de México: Premia Editora, 1991.

Yamamoto, Jorge. Entrevista con Renato Cisneros. "Huancayo es la ciudad que tiene los mejores índices de felicidad”. Nada está dicho. RPP noticias, 6 de marzo de 2018, www. rpp.pe/peru/actualidad/video-jorge-yamamoto-huancayo-es-la-ciudad-que-tiene-los-mejores-indices-de-felicidad-noticia-1108922, consultado el 2 de agosto de 2019. 